\title{
Smart Bin -the hygienic solution for smart waste collection and disposal via IoT
}

\author{
Greeshma LiyaJacob ${ }^{1}$, Nishanth $\mathbf{S}^{2}$, Rahul $\mathbf{R}^{3}$, Ms. Tinu Thomas ${ }^{4}$ \\ ${ }^{1}$ Student, Mangalam College of Engineering,India, greeshmaaamiz1998@ gmail.com \\ ${ }^{2}$ Student, Mangalam College of Engineering, India , unnisasikumar@gmail.com \\ ${ }^{3}$ Student, Mangalam College of Engineering, India, rahul14rhl@ gmail.com \\ ${ }^{4}$ Faculty, Mangalam College of Engineering, India, tinu.thomas@ mangalam.in
}

\begin{abstract}
In this era of development, the major threat we face from being a developed nation are the improper ways of waste collection and disposal. We do witness many of our major cities being dumped with wastes and not being treated properly which could lead to even more crucial health hazards. Thus, an efficient waste collection and management is essential for a clean, green and sustainable environment. This paper presents a proper method to monitor the filling of waste bins and their collection with the help of Internet of Things (IoT). The bin will be placed in all major garbage collection sites and will be monitored remotely from a center, say a municipality board. The system is implemented using an ultrasonic sensor which is connected to node MCU as to monitor waste bin garbage level. The Wi-Fi module is inbuilt in node MCU. The waste bin depth level and weight will be measured and sent via Node MCU Ethernet Shield with an Internet connection to the Cloud platform named Ubidots. The cloud platform stores the collected waste bin level data into IoT database and display the waste bin depth level on online dashboard for real-time visualization. The Ubidots Event manager gives a notification alert to garbage collector's mobile phone via a SMS when the waste bin is nearly filled for immediate waste collection. If the collector fails to take initiative to collect the waste the driver responsible for the collection and disposal will be charged with a penalty. A driver who earns penalty more than three times will face the license cancellation. Therefore, the waste collection and disposal will be more centralized and responsible together with being more effective and systematic. The society will become hygienic and will be able to provide a green environment for a better tomorrow.
\end{abstract}

Key words: Ultrasonic Sensor, Node MCU, Ubidots, Ultrasonic sensor Ethernet Shield, Internet connection IoT database.

\section{INTRODUCTION}

The major threat being faced by India on its path to be a developed nation is its unscientific method for its waste collection and disposal. Being part of all those technological scientific and intellectual developments in all spheres waste generation also increases at the same level. The question where to pause and reflect on is that whether these wastes are

properly treated and disposed or not? Of course, an answer to this question comes as a big NO. Most probably waste generated during any type of production or any other sort are generally being dumped here and their in-core parts of the city being unaware of the fact that where actually a bin is located in the particular[1,2,3] location. If the waste is being dumped in a bin then the bin may be facing issues of overflow and improper treatment which is another major threat for the health scenario existing today. Here a sustainable solution for the problem is being briefed. This comes in association with a local organization such as a municipality of a city where the municipal bodies or the authorities concerned will have a proper monitoring on the location of waste bins, their maintenance, emptying etc. This is made possible by implanting a GPS module in the bin which will help to locate the bin, and a height sensor to predict the total unfilled area in the basket to determine when it should be collected for disposal.

The municipal authorities will have concerned drivers assigned for each bin who will receive an SMS when the basket is being filled. He will collect the particular basket for emptying and will replace the basket properly there back in time which would remove the state of dilemma in people for the disposal of waste when and where possible. The failure from the part of the concerned driver implementing this collection and disposal will have to face a penalty and if the limit of penalties withdrawn by a particular driver exceeds 3 he shall face a licensecancelation since all drivers employed in this are badged licensed drivers. The details of the time of message sending, receival collection of waste replacement of bin etc. will be stored in Ubidots cloud which could be used for future reference 
IoT architecture is being implied here for the real time waste collection monitoring and disposal. IoT helps in improving and optimizing all sorts of waste collection in major cities. Wireless sensors employed here are made useful through the platform of IoT which serves as a promising, emerging technology with solutions to modernize the prevalent technologies. Using wireless sensor networks always ends up with a disadvantage of end-to-end delay which is an important parameter for the Quality of Service $(\mathrm{QoS})$ in data communication. Here end to end delay[4,5,6] is brought to its minimum. While defining the end to end delay could be stated as time taken by a single packet to reach the destination node

from the source node. Here routing path length, shortest path by road to dispose the waste and replacement of the bin as soon as possible etc. are being taken into consideration for making this an effective method of waste disposal in both developed and developing cities.

This paper presents a Smart Bin- a hygienic solution for smart waste collection and disposal (SHSSWCD) via IoT technology on the Cloud[7,8] platform. The sections of the publication paperare organized as follows. Section II describes the system development and the phases of design approach followed by the project. Section III discusses the experimental result of an IoT a Smart Bin- a hygienic solution for smart waste collection and disposal and its performance. At last, section IVprovides the conclusion, remarks and figures out on the ideas forfuture extension of this work.

\section{PROPOSED MODEL}

Taking into consideration the problems created by the overflowing of wastebin in many major cities have met a solution here in the smartbin. The local body authorities of the particular area will be aware about the number of bins fixed, location of each bin, level of waste in each bin, the driver concerned in collecting each bin, the time of collection of each bin for emptying, the time of replacement of each bin etc. When any of the bins are ready for being collected for disposal the bin sends an alert message to the local body authority and the concerned driver for its disposal. The drivers specified here are badged ones with commitment to the local body where they will be imposed with a fine when they fail to collect the bin in time, the alert message will be send to the drivers phone firstly, secondly followed by a warning message. If the driver ignores both the messages, he will be imposed a fine and will be given a negative card. If a driver earns three negative cards he will be fired from the post and will lose his job permanently. The drivers after collecting the waste will dispose all these wastes properly preventing the overflow and public dumping hence contributing to a hygienic tomorrow.

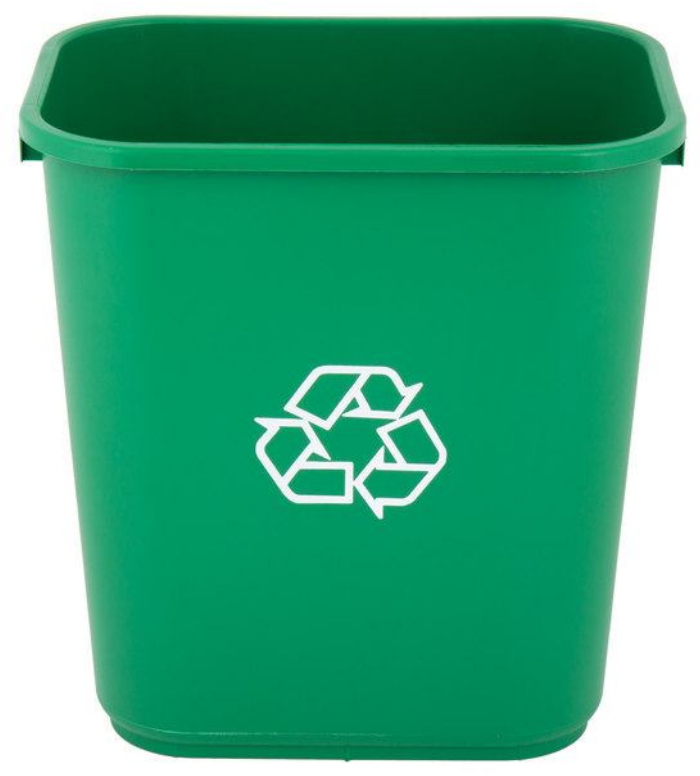

Figure 1: Waste Bin At Selected Locations.

\section{SYSTEM DEVELOPMENT}

This section deals with a brief explanation on the project development methodology and working of the system. The system emphasizes on a $24 * 7$ monitoring system which is designed for monitoring the waste disposal and collection. This smart and organized system is employed for clearing the over dumped wastes from populated areas hence this may contribute to personal and social hygiene. This project uses an ultrasonic sensor which is used for measuring the level of waste in the bin. When the bin is filled an alert message using a GSM module and is being sent from the bin to the employees concerned which include the local body authorities and the drivers concerned in collecting the particular filled bin.Programming in the node MCU is done in such a way that once a particular level of filling is sensed, information as a messageis sent to the local body authority and the driver concerned requesting for cleaning of the dust bin.

The block diagram given below gives the detailed description about the system development in the smart dustbin.

The programming here is done via a node MCU module which has inbuilt Wi-Fi module for the specified internet connectivity that reduces the hardware complexity. The cloud and event manager help in visualization and display of the waste bin depth level data the waste and Ubidots Event manger to notify message to the local body authorities and the drivers concerned via SMS on smartphone when the waste bin 


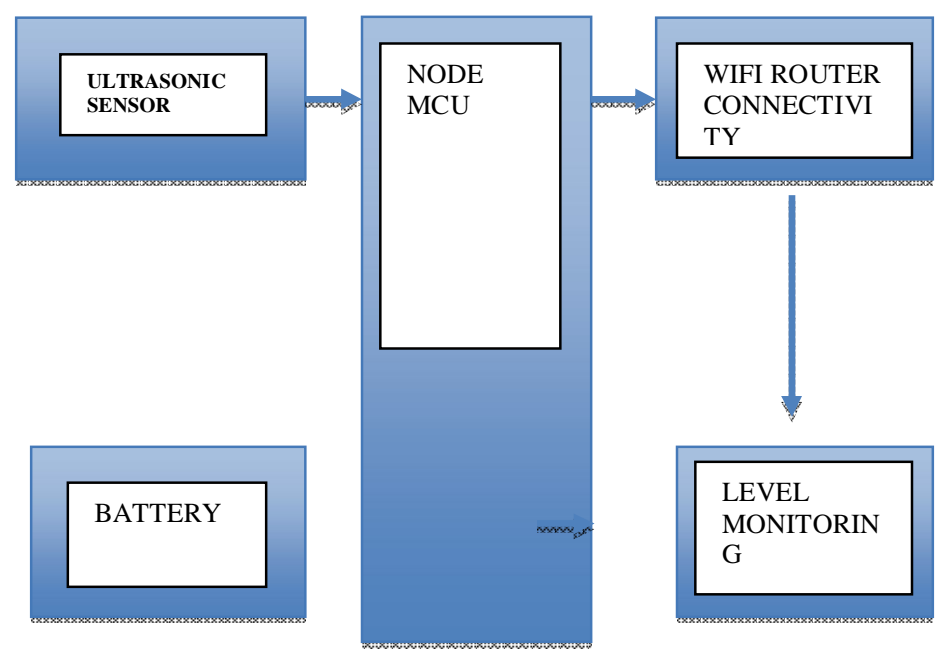

Figure 2: Block Diagram Of SHSSWCD

waste bin is nearly filled.The system development consists of hardware andsoftware development phase. In hardware developmentphase, the Arduino Uno is used as the microcontroller for thesensor node in the development of the project. The sensor node is used to interface the ultrasonic sensor to identify the level of the waste bin.

\section{A.SYSTEM HARDWARE DEVELOPMENT}

\subsection{Node MCU (ESP8266)}

The node MCU circuit used in this project as the major platform of project construction. The motion sensor concerned with the bin detects whenever the waste is deposited in the bin and passes the information to the node MCU and the node MCU passes this information to the local body authorities and the concerned drivers when the bin is filled and ready for collection. The node MCU is used here to link all the information collected from the ultrasonic sensor and other associated sensors to the cloud website concerned in collection and retrieval of all the related information.

Node MCU here is an open hotspot IOT stage which is incorporating firmware running on ESP8266 Wi-Fi SOC. The node MCU has 30 pins in total. Here 9 pins are digital while 1 pin is analog. This is employed for Wi-Fi networking. This system has low power consumption. Here the ESP8266 is employed as the main microcontroller owing to its inbuilt Wi-Fi[9,10] connecting capacity which can be exploited to transmit real time monitored sensor data to web and mobile interfaces. A single board microcontroller type ESP8266 and uses an XTOS operating system. This uses a $128 \mathrm{kByte}$ memory and 4 Mbytes powered by USB. The system uses circuit board functioning as a dual-in-line package which integrates a board of MCU and Antenna.
Here the node mcu platform powers the working of the smart bin for hygienic and smart waste disposal in all growing cities.

\begin{tabular}{|l|l|l|}
\hline $\begin{array}{l}\text { PIN } \\
\text { NO }\end{array}$ & PIN NAME & FUNCTION \\
\hline 1. & VCC & $\begin{array}{l}\text { VCC gives power to the } \\
\text { sensor usually with +5V }\end{array}$ \\
\hline 2. & Trigger & $\begin{array}{l}\text { A trigger is input pin kept } \\
\text { high for 10us to initialize } \\
\text { measurement by sending an } \\
\text { ultrasonic wave }\end{array}$ \\
\hline 3. & Echo & $\begin{array}{l}\text { Echo pin being an output and } \\
\text { goes high for a period of time } \\
\text { which will be equal to the } \\
\text { time taken by the wave to } \\
\text { reach back to ultrasonic } \\
\text { sensor }\end{array}$ \\
\hline 4. & Ground & $\begin{array}{l}\text { This pin is connected to the } \\
\text { ground of the system. }\end{array}$ \\
\hline
\end{tabular}

The general pin out for a node MCU circuit will be as given

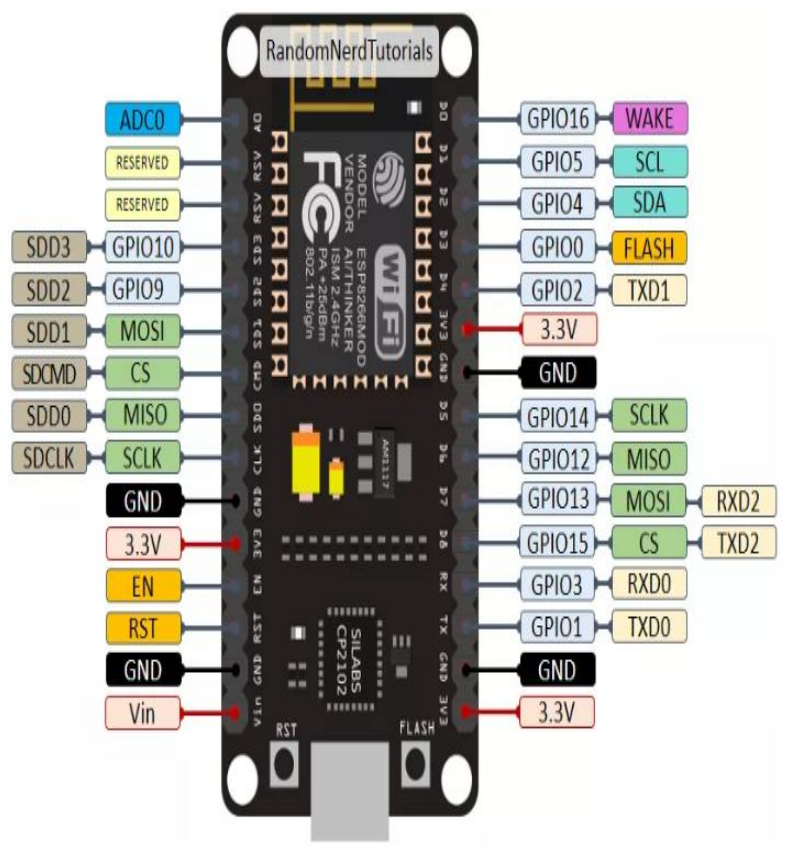

Figure 3: Pin Configuration Of Node Mcu 


\subsection{Ultrasonic Sensor}

The estimation of the bin level can be done through various methods. The distance between the top of the bin and the waste level can be calculated another alternative is to estimate the heaviness of the bin using a weight sensor. Weight estimation cannot be considered as a true method in finding out the level of the bin as the weights of many of the articles dumped in it including plastic cans are negligible. Ultra-nationalistic Sensors are being employed here where they produce ultra-nationalistic wave that gets reflected from the target at the end of the day. Here the concerned trigger is associated with the pin 5 (GPIO) and reverberate is associated with pin 6 (GPIO). Knowing that, the distance can be calculated by:

$2 x$ Distance $=($ Echo Duration $) *($ Ultrasonic Velocity $)$

Here the importance of the $2 \mathrm{x}$ factor in the equation is that the total distance travelled by the ultrasonic wave is being calculated and it is to be accounted in both directions.

\subsection{ESP8266 Wi-Fi Library}

Sending and receiving data in the system is concerned with ESP8266 module in the node MCU which is purely concerned with Wi-Fi activities. The coding in the system is also required for the connection of ESP module to the Wi-Fi in the system. WI-FI. Begin can be effectively used in this coding so that the module could be attached faster to the system.

\section{B. SYSTEMSOFTWARE REQUIREMENTS}

\subsection{MAC AND IP ADDRESS OF THE SENSOR NODE}

Media Access Control address is a unique identifier assigned to a network interface controller for being used as a network address in communications within a network segment. Here the MAC address can be used in collection of the details using the network address in a network. An internet protocol address as a numerical label assigned to each device connected to a computer network uses it for communication. These two addresses are used here in collecting the details like location, capacity of the bin etc.

\subsection{IOT UBIDOTS CLOUD}

Ubidots platform generally is a user focused point and click IOT app builder with data integration in cloud function. The operators and the people concerned like the local body authorities can fill up and retrieve the data concerned about the bin for easier access. Here Ubidots platform is used in recording all the vital details that are associated with the waste collection and disposal. Ubidots is an IoT platform empowering innovators and industries to prototype and scale IoT projects and the same is being employed here. The data that is secured with Ubidots will be protected with two or more replication and will have all types of authentication so that the data will be prevented from any sorts of fraudulent or unauthorized access. The hardware is being connected to this platform so that sending and receiving of data along with the data retrieval is being made possible from the cloud and the data can be made available at any time for any authorized user. This Ubidots platform here serves for data storage and retrieval.

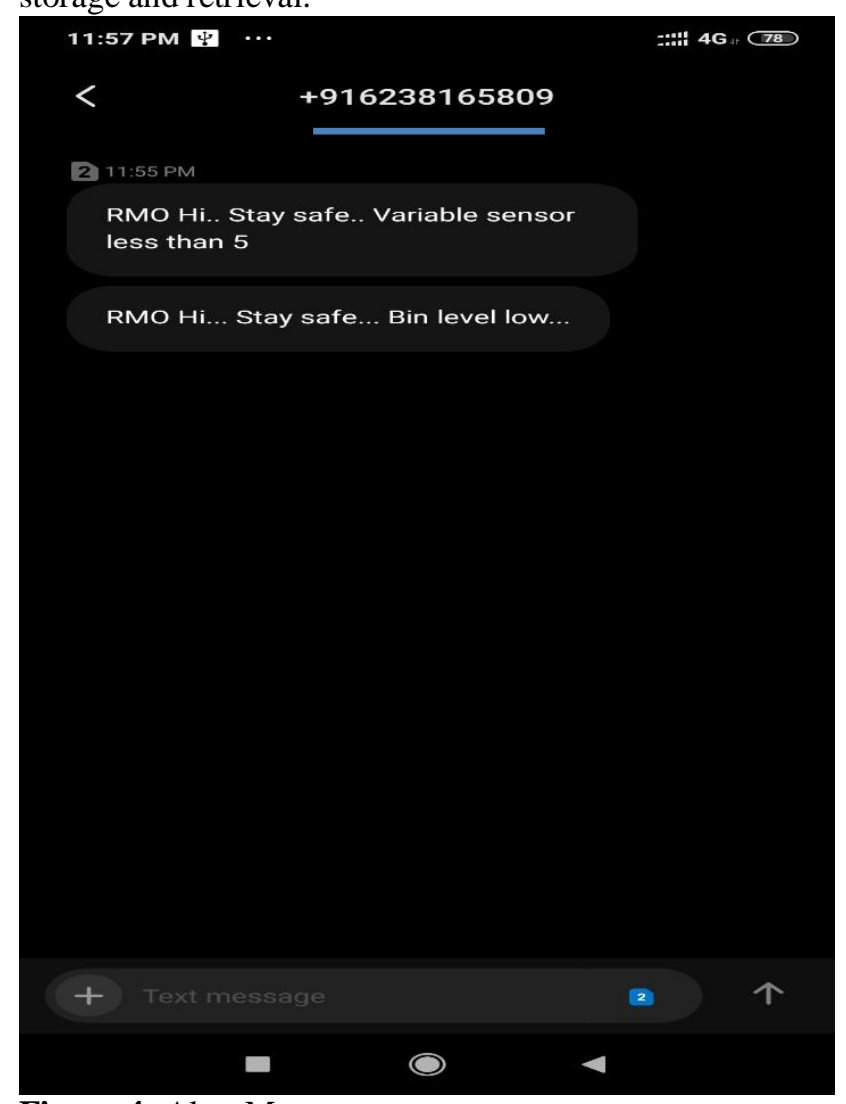

Figure 4: Alert Messages

\section{RESULTS}

The level of waste filled up in the bin can be easily detected by the ultrasonic sensor by the methods employed which and the sensor is connected to the Node MCU. The working of the Node MCU is made possible by the coding given to it. The NodeMCU is connected to a host device using a USB cable at a baud rate of 9600 while the system is connected to the Wi-Fi using a unique username and password which are specified explicitly in the coding section. The proposed system will work effectively in the Node MCU platform as detailed below:

The local body authorities will have the details of the waste bins including the location of the bin, the driver concerned in collecting the bin when it is filled, time and level of the bin at collection etc. stored in the Ubidots cloud platform. The waste will be properly collected preventing the overflow. The dashboard always displays the level filled by the bin in terms of signal strength. 


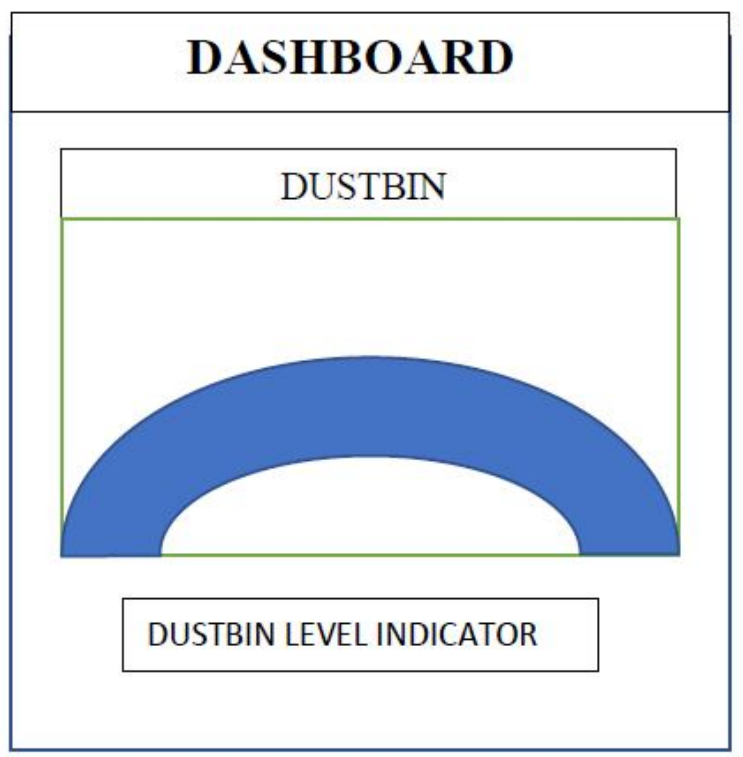

WIFI STRENGTH: $-68 \mathrm{dBm}$

Figure 5:Dashboard Indication About The Level Of Bin.

\section{ADVANTAGES}

1.Efficient method for waste collection.

2.Economically feasible

3.An intelligent solution for common city services.

4.It reduces the number of times the arrival of vehicle which collects the garbage.

5.Method finally helps in keeping the environment clean.

6. time consumption is less.

7. Fill level-based garbage collection route mapping is employed.

8. Optimized route planning is made possible.

\section{FUTURE SCOPE}

The next level advancement for this paper is planned to adapt a sensor that could distinguish solid and liquid wastes apart so that the disposal of segregated wastes could prove to be even larger effect than the latter. Two separate bins with weight sensor will be placed so that the wastes will be separated be the system.

\section{CONCLUSION}

In this paper, we propose a new solution to enhancewaste collection efficiently using the Node MCU with and ultrasonic sensor systems. In this proposed system, the garbage overflow of garbage can be avoided and managed efficiently. This will send an SMS or email to the authorized person through Ubidots platform. The garbage managing system and the facility of collecting the garbage presently doesn't fit to the current requirement. When the garbage level in particular dustbin has reached the maximum level then the employees can be informed and they can immediately take certain actions to empty it as soon as possible. It will reduce the wastage of time, cost and manual labour. It will also prevent the unhygienic conditions causing any diseases. The concerned drivers will be quickly informed about the clearing process and do their work immediately. Thus, this method of monitoring garbage level enhances the overall efficiency of the whole process. Hence better facility of collecting the waste is provided through this paper. Since, thissystem provides the information when the bin getscompletely filled with garbage, it reduces the number oftimes the arrival of vehicle which collects the garbage. Thismethod finally helps in keeping the environment clean. Thus, the waste collection is made more efficient.

\section{ACKNOWLEDGEMENT}

First of all, I thank the almighty God for giving me the strength to venture for such an Enigmatic logical creation in a jovial way. I gratefully take this opportunity to express my profound thanks to our eminent director Er. Biju Varghese, chairman of Mangalam group of Institutions for giving encouragement throughout the course and motivate the students to promote their knowledge. I express my sincere thanks to Dr. Manoj George, the Principal for providing me the facilities to complete my project successfully. They are very grateful for providing the best facilities and environment to do our project. It is with deep sense of gratitude that I express my heartfelt thanks and indebtedness to Dr. Vinodh P Vijayan, Head of Department, Computer Science and Engineering Department, for his encouragement and inspiration. I would like to thank my project guide Ms. Tinu Thomas, Asst. Professor in Computer Science and Engineering Department for his valuable help, sincere guidance, timely suggestions and constant encouragement. I express my deep sense of gratitude to my project coordinator Sujitha.M M, Asst. Professor in computer Science and Engineering Department. Many others have helped me in preparing and processing the project in many ways. It is with pleasure that I acknowledge the help received from all the teachers and staff members of Computer Science and Engineering Department. Finally, I express my sincere thanks to all my friends, parents for their kind presence support and interest to me.

\section{REFERENCES}

[1] Hannan, M., A., Arebey, M., Basra, H. (2010). "Intelligent Solid Waste Bin monitoring and Management System", Australian Journal of Basic and Applied Sciences, 4(10): 5314-5319, 2010, ISSN 1991-8178. 
Greeshma LiyaJacob et al ., International Journal of Advances in Computer Science and Technology, 9(6), June 2020, 39 - 44

[2] Namakambo Muyunda, Muhammad Ibrahim "Arduino-based Smart Garbage Monitoring System Analysis Requirement and Implementation" in 9781-5386-0765- 7/17/\$31.00 @2017 IEEE

[3] "Smart bin: Smart Waste Management System", 2015 IEEE Tenth International Conference on Intelligent Sensors, Sensor Networks and Information Processing (ISSNIP) Demo and Video. Singapore, 7-9 April 2015.

[4] Flora, A. (2009). "Towards a clean environment: A proposal on sustainable and integrated solid waste management system for university Kembangan Malaysia". Report from Alma Flora.

[5] S. Vinoth Kumar, T. Senthil Kumaran, A. Krishna Kumar and Mahanta's Mathapati "Smart Garbage Monitoring andClearance System using Internet of Things" in 2017

[6] Vinodh P Vijayan, Deepti John, Merina Thomas, Neetha V Maliackal, Sara Sangeetha Varghese "Multi Agent Path Planning Approach to Dynamic Free Flight Environment", International Journal of Recent Trends in Engineering (IJRTE), ISSN 17979617 Volume 1, Number 1, May 2009, Page(s): 41-46.

[7] Juby Joseph, Vinodh P Vijayan" Misdirection Attack in WSN Due to Selfish Nodes; Detection and Suppression using Longer Path Protocol" International Journal of Advanced Research in Computer Science and Software Engineering, Volume 4, Issue 7, July 2014, pp. 825-829, ISSN: $2277128 \mathrm{X}$

[8] V P Vijayan, Biju Paul "Multi Objective Traffic Prediction Using Type-2 Fuzzy Logic and Ambient Intelligence" International Conference on Advances in Computer Engineering 2010, Published in IEEE Computer Society Proceedings, ISBN: 978-0-76954058-0, Print ISBN: 978-1-4244-7154-6

[9] Vijayan V P, Gopinathan E "Improving Network Coverage and Life-Time in a Cooperative Wireless mobile Sensor Network " Fourth International Conference on Advances in computing and communications (ICACC) Aug, 2014. Published in IEEE Computer Society Proceedings. Print ISBN: 978-1-4799-4364-7, INSPEC AccessionNumber:14630874,DOI:10.1109/ICACC.20 14.1 6 PP 42-45.

[10] Vinodh P Vijayan, Biju Paul “ Traffic scheduling for Green city through energy efficient Wireless sensor Networks " International Journal of Advanced Trends in Computer Science and Engineering, Volume 8, No.4, July - August 2019, ISSN 2278-3091, https://doi.org/10.30534/ijatcse/2019/81842019. 